\title{
The Relationship between Depression and Anxiety Symptoms and
} Activity of Daily Living in Landmine Explosion Adolescent

\section{Survivors}

\author{
Mehdi Masoumi $^{1}$, Mohammadreza Soroush ${ }^{2}$, Ehsan Modirian ${ }^{3}$, Batool Mousavi ${ }^{4}$, \\ Mohammad Ali Hemmati ${ }^{5}$, Hamid Shokoohi ${ }^{6}$, Naghme Mokhber ${ }^{7}$, Shahriar \\ Khateri $^{8}$, Gholamhossein Arab Sheibani ${ }^{9}$, Seyed Hosein Seyed hoseini davarani ${ }^{10}$, \\ Maryam Hosseini ${ }^{11}$,
}

\section{ABSTRACT:}

Introduction: Physical disability, especially in childhood and adolescence can cause major psychological problems such as depression and anxiety. Burden of landmine in western border cities of Iran caused many disabled survivors through the years after Iran-Iraq war.

Aims: To investigate the potential association of disability of activities of daily living and symptoms of depression and anxiety in adolescents' affected of post war landmine in Iran.

Methods: This study employed two questionnaires for 35 adolescents' survivors of mine explosions; the prevalence of anxiety and depressive symptoms was examined using the Hopkins Symptom Checklist-25 (HSCL-25) and the ability to perform activities of daily living (ADL) was measured by the Barthel index questionnaire. In addition, the association between anxiety and depression with demographic characteristics and activities of daily living was estimated.

Results: Maximum independency was in activities of feeding, bowels, bathing and grooming while highest dependency was in activities of mobility, stairs and dressing. All of the cases have shown depression and the prevalence of anxiety was 31 (88.6\%). An analysis of the data reveals significant association between activities of daily living included dressing, feeding, grooming and bathing with depression and anxiety $(\mathrm{p}<0.05)$. Although eye injured cases had the most complete independency (50\%) in ADL but a significant direct relation was observed between eye impairment and depression $(\mathrm{p}=0.050)$.

Conclusion: Overall, the study suggested that adolescents with physical disability due to landmine explosion may be suffering from depression and anxiety.

Keywords: Activities of Daily Living (ADL), anxiety, depression, landmine, survivor

(C) 2014 M Masoumi, M Soroush, E Modirian, B Mousavi, A Hemmati, H Shokoohi, N Mokhber, S Khateri, G Sheibani, S Hosein Seyed hoseini davarani, M Hosseini,; licensee IJIP. This is an Open Access Research distributed under the terms of the Creative Commons Attribution License (http://creativecommons.org/licenses/by/2.0), which permits unrestricted use, distribution, and reproduction in any Medium, provided the original work is properly cited. 


\section{The Relationship between Depression and Anxiety Symptoms and Activity of Daily Living in Landmine Explosion Adolescent Survivors}

\section{INTRODUCTION}

Mines and unexploded ordnance (UXO) is threatening the lives of civilians in more than seventy countries (NRA, 2010). Some of them have been dealing with this problem for decades. Antipersonnel landmines and other explosive remnants of war (ERW) pose significant and indiscriminate risks to the civilians and is an obstacle to peaceful governance. For the civilians and communities in war-affected countries the presence of these ERWs represents an ongoing threat. In spite of the international agreement that bans anti-personnel mine in the Mine Ban Treaty which signed by many countries in 1997, mine explosions are getting victims every day (UN Mine ban treaty text, 1997). Although most victims are adult men, children by smaller size are more likely to die or suffer blindness, deafness, serious injuries and burns from ERW blast. Child survivors need the considerable social and economic supports and rely on others to carry out common daily activities.

Survivors often experience chronic pain, social exclusion and high levels of psychological distress, all of which are risk factors for poor mental health (Durham et al, 2012). This problem is more prominent in children and as a result of physical trauma, mental health of victims will be at risks and the development of the children is devastated. They suffer from phobias and fear, PTSD, depression, sleep disorders, inability to speak, force to cut education as a result of longterm injuries. Such psychological effects can limit common life of children so require use of rehabilitation for this age group. Precise assessment of activities of daily living (ADL) in survivors of landmine explosion is important for quality care and for measuring the mental health.

Relation to the 1980-88 Iran-Iraq war, western borders of Iran with land mines and unexploded ordnances (UXO) were very dangerous place for life. According to International Committee of Red Cross (ICRC) published in 2014 May, concerted efforts of Iranian Mine Action Centre (IRMAC) has raised awareness of the risks of weapon contamination and the safe practices to minimize exposure to mine-risks (ICRC, 2013). Despite all efforts some residents of these areas are the survivors of landmine explosions. Some of these victims are children and adolescents who suffered different disabilities at the beginning of their life after these casualties.

However, these events at early age with some degree of loss of health and ability made them at risk of psychiatric disorders. Since there is no report on how disability levels from ADL could be meaningfully affect on mental health in landmine survivors, we searched for any relationship between them. The mental health status and activities of daily living in adolescents who were survivors of mine and UXO explosions in western borders of Iran were evaluated. 


\section{MATERIAL AND METHODS:}

\section{Survey design and participants}

We conducted a cross-sectional study of adolescent survivors of landmine explosions. We identified 75 subjects between 12 to 18 in five provinces of Iran's western border who were under the support of Veterans and Martyr Affair Foundation (VMAF) of Iran. We invited them all to participate in the study despite that 35 cases responded to invitations. Information was collected from the participants directly and in an interview for 15 to 20 minutes by a psychiatrist. Socio-demographic background data for all subjects filled in a questionnaire containing following characteristics: age, sex, age of casualty, duration of injury, education after injury and living area. Afterwards, the Hopkins Symptom Checklist-25 (HSCL-25) and Activities of Daily Living (ADL) questionnaire were completed for them.

\section{Questionnaire Design}

\section{Activities of Daily Living (ADL)}

The Activities of Daily Living (ADL) questionnaire was developed to assess basic and self-care activities of daily living and constitute everyday tasks. Reliability and validity of the Persian translated version of the Barthel Index questionnaire was confirmed in a clinical trial (Oveisgharan et al, 2006). The available scores each item are 0 and 5 for two-level items (bathing and grooming), 0, 5, and 10 for three-level items (feeding, dressing, bowels, bladder, toilet use and stairs) and 0, 5, 10 and 15 for four level items (mobility and transfers), ranging from inability to independence. The scores for each of the items are summed. The total score thus ranges between 0 (completely dependent) and 100 (completely independent) with a cutoff score of 65 indicating need for ADL assistance. The test takes approximately 5 minutes to complete.

\section{Hopkins Symptom Checklist-25 (HSCL-25)}

The Hopkins Symptom Checklist-25 (HSCL-25) is a well known and widely used screening instrument that derived from the 90-item Symptom Checklist (SCL-90) (Derogatis et al, 1974). HSCL is a screening tool designed to detect symptoms of anxiety and depression that its use date back to the 1950s. The HSCL-25 uses ten items from the HSCL-25 anxiety cluster and thirteen items from the depression cluster. It also includes two additional somatic symptoms. We recorded their estimates of severity of their symptoms scored on a Likert scale ranging from 1 "not at all" to 4 "extremely". Mean cumulative symptom scores of more than 1.75 for each subcategory have been found to be valid in predicting clinical diagnosis of anxiety and affective disorders in Iran (Bahman et al, 2001). 


\section{Data Analyses}

Statistical analysis was performed using the SPSS (Statistical Package for Social Sciences) version 22.0 package and data are presented as the mean \pm standard error. Pearson correlation coefficients test were used to find the relationship between age, age of casualty and duration of injury with mean scores of HSCL-25 and ADL. P-values less than 0.05 were considered as significant. The differences in means of the HSCL-25 and ADL with sex, education, living area and type of injury explore by independent sample t-test and one-way-ANOVA. Any correlation between the two questionnaires was estimated using chi-square test. Also, to evaluate the significance of mean score of each questionnaire by cut-off point, the one sample t-test was used. There was no missing data, so there was no need to correct for this in the study.

\section{RESULTS:}

The 35 participants completed information on all variables was included in this analysis. The mean age at time of study was $16.15 \pm 1.54$ years; range 13-18 and the mean age of casualty time was $8.82 \pm 3.39$; range $3-15$. The mean duration of injury was $7.32 \pm 3.21$ years; range 2 13. Among the survivors, $26(74.3 \%)$ cases had only one injury and $9(25.7 \%)$ suffered multiple injuries. However, the most common trauma was amputees, $20(57.1 \%)$.

Table1. Sample socio- demographic characteristics $(\mathrm{N}=35)$

\begin{tabular}{lc}
\hline Demographic Characteristics & Frequencies $\mathbf{( \% )}$ \\
\hline Age $\quad$ 14 years old & $5(14.3)$ \\
$\quad 15-18$ years old & $30(85.7)$ \\
Gender & $32(91.4)$ \\
Male & $3(8.6)$ \\
$\quad$ Female & $13(37.1)$ \\
Place of living & $22(62.9)$ \\
Urban & \\
Rural & $30(85.7)$ \\
Education after injuries & $5(14.3)$ \\
Yes & \\
No & $20(57.1)$ \\
Anjuries & $10(28.6)$ \\
Emputees & $7(20.0)$ \\
Ear problems & $3(9.1)$ \\
Spinal cord injuries & $7(20.0)$ \\
Other injuries &
\end{tabular}




\section{The Relationship between Depression and Anxiety Symptoms and Activity of Daily Living in Landmine Explosion Adolescent Survivors}

The mean score for Activities of Daily Living was estimated $77.43 \pm 19.34$. Maximum "independency" was in activities of feeding, bowels, bathing and grooming while highest "dependency" and "need to help" was in activities of mobility, stairs and dressing (Table 2). No one scored 0-20 (absolutely dependency), twelve cases (34.3\%) scored 21-60 and had severe dependence, 11 subjects (31.3\%) showed moderate dependency by score 61-90, scores of 5 cases (14.3\%) were 91-99 indicated slight dependency and 7 survivors (20\%) scored 100 and were complete independent.

Table2. ADL among adolescents' survivors of landmines

\begin{tabular}{|c|c|c|c|c|}
\hline Daily Activities & $\begin{array}{c}\text { Independent } \\
(\%)\end{array}$ & $\begin{array}{c}\text { Need to help } \\
(\%)\end{array}$ & $\begin{array}{c}\text { Unable } \\
(\%)\end{array}$ & ADL mean score \\
\hline Feeding & $27(77.1)$ & $8(22.9)$ & $0(0 \%)$ & $8.85 \pm 2.13$ \\
\hline Bathing & 24 (68.6) & - & $11(31.4)$ & $3.42 \pm 2.35$ \\
\hline Grooming & $24(68.6)$ & - & $11(31.4)$ & $3.42 \pm 2.35$ \\
\hline Dressing & 17 (48.6) & 17 (48.6) & $1(2.9)$ & $7.28 \pm 3.80$ \\
\hline Bowels & $25(71.4)$ & $8(22.9)$ & $2(5.7)$ & $8.28 \pm 2.95$ \\
\hline Bladder & $21(60)$ & $12(34.3)$ & $2(5.7)$ & $7.71 \pm 3.05$ \\
\hline Toilet use & $22(62.9)$ & $12(34.3)$ & $1(2.9)$ & $8.00 \pm 2.76$ \\
\hline $\begin{array}{l}\text { Transfers (bed to } \\
\text { chair and back) }\end{array}$ & $23(65.7)$ & $11(31.4)$ & $1(2.9)$ & $12.14 \pm 4.42$ \\
\hline $\begin{array}{l}\text { Mobility (on level } \\
\text { surfaces) }\end{array}$ & $11(31.4)$ & $19(54.3)$ & $5(14.3)$ & $10.85 \pm 3.31$ \\
\hline Stairs & $19(54.3)$ & $14(40.0)$ & $2(5.7)$ & $7.42 \pm 3.06$ \\
\hline
\end{tabular}

Due to the cut-off point $\geq 1.75$ for HSCL-25 all the cases have shown depression and the prevalence of anxiety was 31 (88.6\%). Depressions and anxiety mean scores $(4.45 \pm 1.71 \& 2.58$ \pm 0.07 , respectively) had no significant difference between boys and girls. The results showed that the mean scores of anxiety, depression and total HSCL was significantly higher than normal Iranian population $(\mathrm{p}<0.001)$. 
In evaluating the relationship between each of activities of daily living with depression and anxiety, dressing, feeding, grooming and bathing were significantly associated with these mental problems (Table 3). No relation between the mean score of depression and anxiety with ADL was observed ( $\mathrm{p}=0.459 \& \mathrm{p}=0.132$, respectively). No significant correlation was found between the mean scores of depression and anxiety with demographic variables. Moreover, the mean scores of ADL were not significantly correlated with demographic characteristics.

Table 3. Relationship between ADL with depression and anxiety among adolescents' survivors of landmines

\begin{tabular}{ccc}
\hline ADL Activity & Depression (P value) & $\begin{array}{c}\text { Anxiety (P } \\
\text { value) }\end{array}$ \\
\hline Feeding & 0.008 & 0.035 \\
Bathing & 0.01 & $\mathrm{p}>0.05$ \\
Grooming & 0.05 & $\mathrm{p}>0.05$ \\
Dressing & 0.001 & 0.013 \\
\hline
\end{tabular}

The analysis revealed eye injury was significantly related to depression and ADL mean score $(\mathrm{p}=0.050 \& \mathrm{p}=0.038$, respectively). As well as, a complete significant association was observed between ear impairment and the mean score of the anxiety ( $\mathrm{p}=0.002)$. However, it was not found any relationship between amputation, SCI and multiple injuries with the mean score of depression, anxiety and ADL.

\section{DISCUSSION:}

Our results showed disabilities to perform activities of daily living can cause anxiety and depression. The importance of this study is due to no similar study has been conducted in the adolescent survivors of landmine explosions. Also, at the time of study, total of Iranian survivors between 13 to 18 years were 73 and the sample size in this study was approximately half of the total $(47.9 \%)$. The standardized cut-off scores in HSCL-25 showed our cases had mean scores above Iranian general population. Estimating rates of symptoms of anxiety and depression in survivors, depression was observed in all subjects and nearly ninety percent of cases had anxiety. Not surprisingly, correlations of depression and anxiety with ADL mean score were not significant as a result of high frequency of these mental problems. Unlike previous studies, no significant gender differences were seen regarding depression and anxiety. In other studies, significant difference between anxiety and depression frequencies in boys and girls is quite evident and the frequency in women is almost twice for men (Matthis et al, 2013). However, it is 


\section{The Relationship between Depression and Anxiety Symptoms and Activity of Daily Living in Landmine Explosion Adolescent Survivors}

possible that due to the low number of female subjects in this study (32 versus 3) the difference could not assess between the sexes.

In half of the daily activities, two thirds of subjects were independent. Highest level of independency was observed in feeding, there was no one who is unable in this activity and only one fifth of survivors need assistance in feeding. However, the highest level of disability was estimated in bathing and grooming. The lowest level of independence was mobility on level surfaces and more than half of the subjects needed help in this activity that can be due to the high frequency of amputation in survivors.

Disability in activities such as taking bath and dressing and also need to help in feeding had significant relation with depression. One explanation for this is that such activities are primary and essential activities of daily living so it can cause depression and stress. Also, parents with a disabled child felt severe sadness and family relationships were all affected (Esine et al, 2007). As a result, it can affect children and they were suffering from depression too. On the other hand, people with more severe physical disability experienced lower levels of body esteem than people with milder physical disabilities and able-bodied people (George et al, 2004).

Moreover, mean scores on the HSCL-25 for the total scale did not have significant gender differences which could be due to the low number of girls than boys. Although significant relationship was not obtained in daily activities, but mean score of daily activity was more than ninety in 3 women participated in this study that it showed a slight dependency.

The study also examined correlates of ability to perform ADL with the type of injury. Despite the higher frequency of amputation among the victims, no significant association was observed between depression, anxiety and disability of activities of daily living with this injury. Vision problem was the only injury connected with ADL means score. Unlike previous study support the fact that vision loss has direct association with ADL disability, our results indicates that cases that have impaired vision had more ability to handle their activities of daily living (Vijaya et al, 2003). However, the rate of depression and anxiety was higher in vision impairment group despite they were more independent in ADL. Half of the survivors with vision impairment were completely independent in their activity of daily living and the rest of the eye injured victims had moderate to slight dependency in ADL.

Chronic physical conditions were a significant risk factor for behavior problems, independent of socio-demographic variables (Joan-Carles et al, 2008). Also, it is plausible that people with visual impairment are more likely to experience problems with functioning, which in turn leads to depression (Maite et al, 2009). This is strongly supported by our results in adolescents'

survivors with visual impairment who show the high prevalence of depressive-anxiety symptoms. Furthermore, living with hearing loss, in many aspects, is like living with a chronic illness. According to previous studies, Hearing impaired children and adolescents basically suffer from the psychiatric illnesses such as anxiety and depression (Lier, 2013). This fact is also 


\section{The Relationship between Depression and Anxiety Symptoms and Activity of Daily Living in Landmine Explosion Adolescent Survivors}

confirmed by the results of our study that was conducted on adolescents and showed ear disorders caused anxiety in this age group.

The literature in young-adult populations shows that anxiety disorders are associated with increased disability (Turner et al, 1998; Fyer et al, 1996; Sheehan et al, 1996). Our finding also showed that anxiety was associated with disability of feeding and dressing. One interpretation of this is that being incapable of the simplest basic activities in daily living can be a risk factor for increasing anxiety and stress. There was no correlation between anxiety and depression with amputation, SCI and multiple injuries, but this could be due to small sample size. Overall, the study suggested that people with physical disability due to landmine explosion may be particularly vulnerable to mental problems. One limitation of this study was the relatively small sample size and also all mine victims at the age of 13 to 18 did not participated in this study. Anyway, there is no similar study to investigate the presence of depression and anxiety in adolescents' survivors of landmine and also association between ADL disabilities with this mental problem; so these are the strengths of this study.

\section{CONCLUSION:}

Burden of landmine, many of residents of Iran's west regions are blast victims and among them, there are a significant number of children and adolescent. Between the survivors, cases with different percentages of physical disabilities can be found. In this study we showed that inability to perform activities of daily living can cause depression and anxiety and the incidence of these mental problems can be associated with the type of injuries. Given that this age group is very susceptible, especially when they compared their abilities with other teens, further studies for any further help looks necessary.

\section{REFERENCES:}

1. Bahman. Najarian \& Iran. Davoodi. Construction and Validation of SCL-25, short form of SCl-90. Journal of Psychology. 2001; 5(2): 136-49.

2. Derogatis LR, Lipmann RS, Rickels K.The Hopkins symptoms checklist (HSCL): a selfreport inventory. Behav Sci. 1974; 19:1-15.

3. Durham Jo, Peter S Hill and Damian Hoy. The underreporting of landmine and explosive remnants of war injuries in Cambodia, the Lao People's Democratic Republic and Viet Nam. Bulletin of the World Health Organization. 2012; 91: 234-236.

4. Esine Sen and Sabire Yurtsever. Difficulties Experienced by Families with Disabled Children. Journal for Specialists in Pediatric Nursing. 2007; 12(4): 238-52.

5. Fyer AJ, Katon W, Hollifield M, et al: The DSM-IV panic disorder field trial: panic attack frequency and functional disability. Anxiety 1996; 2:157-166. 
6. George Taleporos \& Marita P. McCabe. The relationship between the severity and duration of physical disability and body esteem. Psychology \& Health. 2004; 20(5): 637650.

7. International Committee of the Red Cross (ICRC), Annual Report 2013 - Islamic Republic of Iran, 14 May 2014, available at: http://www.refworld.org/docid/5374af3.html [accessed 18 June 2014].

8. Joan-Carles Surís, Pierre-André Michaud, Christina Akre, Susan M. Sawyer. Health Risk Behaviors in Adolescents with Chronic Conditions. PEDIATRICS. 2008; 122(5): 111318.

9. Lier, Fride Bysveen. Mental health in deaf and hearing impaired children and adolescents. Prosjektoppgave, University of Oslo. Master of thesis. 2013. http://urn.nb.no/URN:NBN:no-35972 .

10. Maite Garaigordobil and Elena Bernarás. Self-concept, Self-esteem, Personality Traits and Psychopathological Symptoms in Adolescents with and without Visual Impairment. The Spanish journal of psychology. 2009; 12(1): 149-160.

11. Matthis Schick, Naser Morina, Richard Klaghofer, Ulrich Schnyder and Julia Muller. Trauma, mental health, and intergenerational associations in Kosovar Families 11 years after the war. European Journal of Psychotraumatology. 2013; 4: 21060.

12. National Regulatory Authority for UXO/Mine Action Sector in Lao PDR (NRA)/UNDP: National Survey of UXO Victims and Accidents. PHASE 1; 2010.

13. Oveisgharan S, Shirani S, Ghorbani A, et al. Barthel index in a Middle-East country: translation, validity and reliability. Cerebrovasc Dis 2006; 22:350-354.

14. Sheehan DV, Harnett-Sheehan K, Raj BA: The measurement of disability. Int Clin Psychopharmacol 1996; 11(3):89-95.

15. Turner RJ, Noh S: Physical disability and depression: a longitu dinal analysis. J Health Soc Behav 1988; 29:23-37.

16. UN Mine ban treaty text, CONVENTION ON THE PROHIBITION OF THE USE, STOCKPILING, PRODUCTION AND TRANSFER OF ANTI-PERSONNEL MINES AND ON THEIR DESTRUCTION: http://www.un.org/Depts/mine/UNDocs/ban_trty.htm.

17. Vijaya K. Gothwal, Jan E. Lovie-Kitchin and Rishita Nutheti. The Development of the LV Prasad-Functional Vision Questionnaire: A Measure of Functional Vision Performance of Visually Impaired Children. Investigative Ophthalmology \& Visual Science. 2003; 44(9): 4131-9. 


\section{About Authors:}

Mehdi Masoumi, (MD, Janbazan Medical and Engineering Research Center (JMERC), Tehran, Iran)

Mohammadreza Soroush, (MD, Janbazan Medical and Engineering Research Center (JMERC), Tehran, Iran)

Ehsan Modirian, (MD, MPH, Emergency medicine, Boali Hospital, Qazvin University of Medical Sciences, Qazvin, Iran)

Batool Mousavi, (MD, MPH, Social Medicine, Janbazan Medical and Engineering Research Center (JMERC), Tehran, Iran)

Mohammad Ali Hemmati, (MD, MPH, Psychiatrist, Janbazan Medical and Engineering Research Center (JMERC), Tehran, Iran)

Hamid Shokoohi, (MD, MPH, Emergency medicine, Associate Professor, Department of Emergency Medicine, George Washington University, Washington DC, USA)

Naghme Mokhber, (MD, MPH, Professor of Psychiatry and Behavioral Sciences Research Center, Mashhad University of Medical Sciences, Mashhad, Iran)

Shahriar Khateri, (MD, PhD, Medical Toxicologist, Janbazan Medical and Engineering Research Center (JMERC), Tehran, Iran)

Gholamhossein Arab Sheibani, (MD, Janbazan Medical and Engineering Research Center (JMERC), Tehran, Iran)

Seyed Hosein Seyed hoseini davarani, (Emergency medicine, Assistant Professor of Tehran University of Medical Science, Tehran, Iran)

Maryam Hosseini, (Researcher of Janbazan Medical and Engineering Research Center (JMERC), Tehran, Iran.) 